Paddy and Water Environment, DOI: 10.1007/s10333-013-0371-5.

\title{
Measurement of soil salinity using electromagnetic induction in a paddy with a densic
} pan and shallow water table

Juan Herrero • Wayne H. Hudnall

6 Juan Herrero

7 Estación Experimental de Aula Dei, CSIC, PO Box 13034, 50080 Zaragoza, Spain

8 e-mail: jhi@eead.csic.es; phone + 34976716 152, fax 34976716145

9 Wayne H. Hudnall (deceased)

10 Department of Plant and Soil Science, Texas Tech University, Lubbock, TX 79409, USA

12 Abstract Rice (Oryza sativa L.) has become a monoculture in the saline lands of the Ebro 13 Valley, Spain. The studied farm has produced rice since the 1970s; one exception was 1999,

14 which enabled us to map the soil salinity. The farm had lateral salinity variations mirrored by 15 the development of rye grass (Lolium multiflorum Lam.) planted in 1999. Our objective is to 16 prove the value of a non-deterministic method using electromagnetic induction (EMI) to map 17 the salinity of the rootable layer in the unfavorable circumstances of a paddy having shallow 18 saline and quasi-artesian water table underneath a continuous densic layer. From our EMI 19 readings and soil sampling, we draw a map of the electrical conductivity of saturated paste extracts (ECe) of the upper soil layer $(0-40 \mathrm{~cm})$, with ECe ranging from $1.6 \mathrm{dS} \mathrm{m}^{-1}$ to $20.8 \mathrm{dS}$

$21 \mathrm{~m}^{-1}$ and a mean of $7.9 \mathrm{dS} \mathrm{m}^{-1}$. A main achievement was the establishment of an easy procedure 22 not requiring either: (i) knowledge regarding the salinity of the water table or the relationships 23 between EMI readings and the deep soil composition; or (ii) a normal distribution of the EMI 24 readings or of the ECe; or (iii) assumptions about the physical dimensions of the EMI 25 readings. Our procedure will allow ECe to be mapped on other similar salt-affected paddies, 26 helping to decide if a paddy can be planted with alternate crops for production, weed control, 27 or soil structure improvement.

28 Key words: Irrigation $\bullet$ Paddy soil $\bullet$ Rice $\bullet$ Spain 


\section{Introduction}

Puddled rice is a sound productive choice for agriculture in saline Mediterranean inland areas where irrigation water of low electrical conductivity is available. This is the case for the

33 Flumen irrigation district (Nogués et al. 2000), located in the semiarid Central Ebro Valley,

34 NE Spain, where rice has been grown for about 60 years as the only economically feasible 35 crop due to soil salinity, even though rice is not a highly salt-tolerant crop. As long as the soil 36 is puddled and the paddy is flooded, the high-quality irrigation water prevents the saline 37 groundwater underneath the puddle zone from contaminating the paddy rice rooting zone. The 38 soil is puddled using the fallow straw to develop a compact soil pan at about $40 \mathrm{~cm}$ depth, which is comparable to a continuous adobe layer. This impervious densic pan prevents rice roots penetration, decreases infiltration and impedes the rise of saline water. Rice yields are

41 economically satisfactory because the rice plants depend only on the soil layer overlying the 42 pan and on the water (about $2000 \mathrm{~mm} \mathrm{yr}^{-1}$ ) required in this area to maintain rice under 43 continuously flowing water with a depth of about $10 \mathrm{~cm}$ (Playán et al. 2008).

The oldest and most typical paddies in Flumen are located within the landscape depressions. Shallow, saline water tables are common in these depressions because of paddy rice from May $1^{\text {st }}$ to September, and because the upper conterminous lands are irrigated producing subsurface flow into the depressions through the saliferous strata. Most paddies remain waterlogged or muddy throughout the year. Moreover, the subsurface soil is oversaturated. In most years, these conditions hinder soil sampling with commonly available tools, as well as the use of field techniques based upon the electrical or the electromagnetic

51 properties of the soil.

Because of these reasons, there is essentially no salinity data for the root-usable soil

53 volume by rice or by rotationary crops. Electromagnetic induction (EMI) measurements and

54 limited strategically located field data could produce both maps and average salinity values for

55 this layer if it were not flooded and/or saturated. For interpretation in agricultural systems, the

56 EMI readings must be converted to a standard measure of soil salinity, such as the electrical 57 conductivity of the saturation extract (ECe). 
Researchers have used EMI to map soil salinity within plots around the world, as 59 reviewed by Rhoades et al. (1999) and also for Flumen and other irrigation districts in the 60 Ebro Valley (Amezketa 2006). The soil depth investigated was about $1 \mathrm{~m}$ in most cases, but 61 EMI data also have been correlated with soil salinity at other depths in the Flumen district 62 (Herrero et al. 2003; Nogués et al. 2006; Playán et al. 2008; Herrero et al. 2011). However, the 63 permanence of a saline water table under the densic pan in the old paddies of Flumen's

64 irrigated districts raised the question whether EMI would be applicable for salinity assessment 65 of the rooting layer above the densic pan. Under supersaturated or flooded conditions soil 66 salinity cannot be measured by the classical sampling methods. Moreover, rice development 67 does not mirror these saline differences provided it is cultivated as a paddy with flowing fresh 68 water.

Most salinity problems in paddies occur in river deltas or other coastal areas, and are caused by seawater intrusion or low-quality irrigation water; however, few studies have used

71 EMI to measure the soil salinity of paddies (Enrique et al. 2005; Li et al. 2013); rather, most

72 EMI surveys in paddy plots have been conducted on non-saline soils in humid areas (Aimrun 73 et al. 2007, 2011; Ezrin et al. 2010; Islam et al. 2011) for purposes other than soil salinity 74 mapping. To our knowledge, no published studies have used EMI to measure agricultural 75 salinity in the unfavorable conditions of a paddy that is underlain by a shallow saline water 76 table.

One of the most popular EMI instruments is the EM38 sensor (Geonics Ltd., 78 Mississauga, Ontario, Canada). EM38 is easily hand-held because it weighs only about $3.6 \mathrm{~kg}$ 79 and is only $1.05 \mathrm{~m}$ long (Fig. 1). EM38 is based on two parallel coils at a fixed distance of $1 \mathrm{~m}$ 80 (Fig. 1 a). A primary magnetic field created by the emitter coil induces small currents in 81 conductor materials such as the soil. The secondary magnetic field created by these currents, 82 superimposed on the primary magnetic field, excites the receiver coil with an intensity that is 83 read on a dial. The intensity often differs according to whether the sensor is placed with its 84 coils vertical (Fig. 1b) or horizontal (Fig. 1c), due to the different pattern of contribution to the 85 signal made by the successive soil layers, with a greater relative contribution from shallow 86 layers if the coils are horizontal (Rhoades et al. 1999). These contribution patterns and other 87 details of the EMI response have been discussed in McNeill (1980) and in López-Bruna and 
Herrero (1996). According to these authors, the physical dimensionality of the signal, and thus its units, can be controversial. This matter is overcome by adopting an empirical method without assigning units to the EMI readings. Our approach to converting the EMI readings into

91 ECe estimations is statistical, and not deterministic; i.e., it relies on targeted sampling

92 strategies and regression calibrations, as described by Lesch et al. (2005).

The literature provides few examples of the use of EM38 for salinity assessment in

94 paddies with conditions similar to Flumen, where the EMI signal is influenced by the non95 targeted saline and supersaturated deep layers. EM38 has been used by Li et al. (2013) for generating a three-dimensional model of soil salinity in a paddy including the deep soil. In the

97 present article we avoid to consider the relative contribution of the non-targeted deep layers to 98 the EM readings. We mapped the soil salinity of a target layer $(0-40 \mathrm{~cm})$ in a saline paddy 99 using the classical calibration of EMI readings with ECe measured in a few soil samples. The 100 objective was to simplify the soil salinity mapping in puddled soils by testing that assumptions 101 about (i) the composition of the oversaturated saline layer below the densic pan, (ii) the normality of the regressed data, and (iii) the physical dimension of the EMI readings, are unnecessary. The mapping has practical implications for agricultural management.

\section{Materials and methods}

107 The studied farm is located in the Ebro Valley, NE Spain (Fig. 2), municipality of Almuniente.

108 The area was intensively leveled for basin and border irrigation in the 1950's. The climate is 109 semiarid, with mean annual temperature of $15.3^{\circ} \mathrm{C}, 434 \mathrm{~mm}$ precipitation, and $1188 \mathrm{~mm}$ 110 reference evapotranspiration $\left(\mathrm{ET}_{0}\right)$, according to the records of the Almuniente weather 111 station, located $2 \mathrm{~km}$ from the farm. The parent material for the soils is Quaternary deposits of 112 alternating millimetric layers of silt and sodic clay from Miocene saliferous strata that outcrop 113 along the surrounding slopes. Soils are saline or saline-sodic, with weak structure, and are 114 classified as Oxyaquic Xerofluvents (Soil Survey Staff 2010).

115 The farm, with an area of 14 ha, is divided into 7 plots as shown by the aerial photograph 116 of Fig. 3. Plots are in steps descending from plot 1 to plot 7, and with a berm between them. 
117 Irrigation water is distributed to each plot by individual gates in an elevated irrigation ditch

118 built in concrete. Table 1 shows composition data for a soil profile described in July 1979 at

119 plot no. 1 plus the ECe for synthetic layers of $20 \mathrm{~cm}$ depth calculated with the method of

120 Herrero and Pérez-Coveta (2005) by averaging ECe with data from six cores taken at two sites

121 of plot no.1 in 1979-1980, and by averaging the data from six cores taken in 1999-2000 at the

122 same sites. The ECe of the upper meter of the soil in plot no. 1 ranged from 40 to $45 \mathrm{dS} \mathrm{m}^{-1}$,

123 and sodium adsorption ratio (SAR) from 85 to 100 in 1979-80. In 1999-2000, the ECe was 2

$124 \mathrm{dS} \mathrm{m}^{-1}$ and SAR was about 2 (Herrero 2008). This noticeable decrease can be attributed to the

125 continuous flooding of the paddies with fresh, running irrigation water. A saline water table

126 with an electrical conductivity ranging from 0.95 to $4.87 \mathrm{dS} \mathrm{m}^{-1}$ (mean $2.28 \mathrm{dS} \mathrm{m}^{-1}$ ), was

127 measured during February and August, 1999. This range of salinity is common during the

128 irrigation season. The soil surface was wet and often ponded for most of the field visits during

129 1999-2000. After stopping the flooding to allow the harvest of rice, in September 1999, the

130 entire farm was planted with Promenade Italian rye grass (Lolium multiflorum Lam., var.

131 Westerwoldicum). In November, it was less than $15 \mathrm{~cm}$ tall in many areas of the farm. Rye

132 grass planted in plots no. 3 to 6 had irregular cover, with spots where the seed did not

133 germinate. The circumstance of having a non-flooded crop provided an opportunity to map the

134 root zone soil salinity.

135 EMI readings were performed with a hand-held EM38 sensor. The EMI readings and soil

136 sampling were conducted from orthogonal grids. After marking the grid points with stakes,

137 EM38 readings were obtained from these sites a few days after irrigation. Soil temperature

138 was measured at 20 and $40 \mathrm{~cm}$ depth. At each site, the EM38 readings were taken with coils in

139 horizontal and in vertical position. After correcting for average temperature according to

140 Rhoades et al. (1999, page 6) to the standard temperature of $25^{\circ} \mathrm{C}$, and dividing by 100 to

141 simplify formulations, these EM38 readings were designated as EMh for horizontal coils and

142 as EMv for vertical coils. EMh and EMv give different information owing to their different

143 relative response vs. depth depending on the position of the coils (MacNeill 1980, Figure 6).

144 Table 2 summarizes the measurements with EM38. 
On September 10, 1999, the lateral gradient of soil salinity on the entire farm was established by the first EMI survey covering about 14 ha at the nodes of an orthogonal grid of

$14750 \mathrm{~m} \times 50 \mathrm{~m}$, producing a total of 100 reading sites. On November 19, 1999, three, $6 \mathrm{~cm}$ 148 diameter perforated vertical pipes were installed to a depth of $150 \mathrm{~cm}$ (Fig. 3) to measure the water table level. Two pipes, T1 and T2, were located within plot no. 2 at $0.5 \mathrm{~m}$ from the borders and $30 \mathrm{~m}$ and $180 \mathrm{~m}$ from the road, respectively. The third pipe, T3, was located within plot no. 1 .

On December 15, 1999, 250 sites were located in the selected plot no. 2 (2.3 ha) at the nodes of an orthogonal $10 \mathrm{~m} \times 10 \mathrm{~m}$ grid (Fig. 4), more dense at the corner where machinery wreck disturbed the EMI signal. After completing the EMI readings, 40 sites were chosen for

155 further soil sampling up to $40 \mathrm{~cm}$ depth based on the following criteria: (i) to span the range of 156 the EMI readings, and (ii) to accomplish approximately uniform coverage across plot no. 2.

157 Soil samples for gravimetric water content $(\theta)$ determination were transported to the lab 158 in hermetically sealed cans and weighed the same day. Samples for salinity determination, 159 transported in polyethylene bags, were air-dried and ground in a sieving mill with 2-mm mesh 160 openings. All subsequent determinations were performed on the fine earth $(<2$-mm fraction).

161 Percent of saturation (PS) of the saturated paste and ECe reported in $\mathrm{dS} \mathrm{m}^{-1}$ at $25^{\circ} \mathrm{C}$ were 162 determined for each sample (United States Salinity Laboratory Staff 1954), with PS used as a 163 surrogate of textural composition. The major ions $\left(\mathrm{Ca}^{2+}, \mathrm{Mg}^{2+}, \mathrm{Na}^{+}, \mathrm{K}^{+}, \mathrm{CO}_{3}{ }^{2-}, \mathrm{HCO}_{3}^{-}, \mathrm{Cl}^{-}\right.$, $164 \mathrm{SO}_{4}{ }^{2-}$ ) from six soil sites chosen at random (Fig. 4) were determined from the saturation 165 extracts, and the SAR calculated; $\mathrm{pH}$ was measured on the same extract ( $\mathrm{pHe}$ ).

166 On April 19, 2000, the EMI readings were not consistent with the visual symptoms of 167 salinity because the soil was too dry in some areas, i.e., outside the allowable range of soil 168 moisture for EMI measurements of not less than about one-half of field-capacity water content 169 (Rhoades et al. 1999). The rye grass showed maximum development within plot no. 2, but 170 broad, bare surfaces showing salt efflorescence were noted.

171 EMh, EMv, and lab data were analyzed using histograms, centrality measures (mean, 172 median, quartiles) and dispersion measures (variance, standard deviation, and coefficient of 
173 variation). Normality was studied using the Kolmogorov-Smirnov test. Boxplots were drawn

174 according to the conventions established by Chambers et al. (1983).

175

176 Relationships between EMh and EMv

177

178 For each of the two dates of calibration, EMh and EMv were examined and their relative

179 magnitudes visualized by histograms, scatter diagrams, and boxplots. The regressions between

180 EMh and EMv allowed the determination of colinearity between the horizontal and the vertical

181 reading modes for several groupings of EMI data sets.

182 We tested two groupings by paralleling Rhoades et al. (1999) when they conducted 183 separate calibrations of the EMI sensor depending on if the deep soil salinity is predominant

184 ("regular profiles"), or not ("inverted profiles"). We used two arbitrary thresholds; the first 185 was $\mathrm{EMv} \geq \mathrm{EMh}$, and the second $\mathrm{EMv} \geq \mathrm{EMh}+0.1$ to obtain different batches of data for 186 regressions. Maintaining our empirical approach, the purpose of our thresholds was not to 187 investigate or to hypothesize about the vertical distribution of salinity, water content or other 188 soil characteristics influencing the EMI readings. Notwithstanding, for sake of brevity we use 189 the denominations "regular" and "inverted".

191 Regressions

193 ECe was regressed on EMh and EMv to estimate soil salinity from EMI readings of those sites 194 without soil sampling. Independent calibrations of the EM38 with ECe were tested for the sites 195 with high contribution to EMI response from the deep layers, using the two above mentioned 196 thresholds.

197 The frequency distributions were not Gaussian, a very common case for soil salinity 198 (Isaaks and Srivastava 1989). Box-Cox transformations (Myers 1990) were applied trying to 199 obtain normality, without satisfactory results. Multiple linear regressions were applied to 200 check the relationship of ECe with EMh and EMv. For the multiple regressions of ECe on 
201 EMh and EMv, EMh and EMv were transformed to their natural logarithms. Colinearity

202 between these two measurements was reduced by taking the difference between the natural

203 logarithms of EMh and EMv as the second explanatory variable, instead of EMv (Lesch et al.

204 1992).

205 As the above methods did not improve the results of the linear regression, a

206 nonparametric simple regression was performed using the Theil method (Daniel 1990; Glaister

207 2005), which estimates the slope coefficient and the intercept of a regression line. For a set of

$208 n$ pairs of observations $\left(x_{1}, y_{1}\right),\left(x_{2}, y_{2}\right), \ldots,\left(x_{i}, y_{i}\right),\left(x_{j}, y_{j}\right), \ldots,\left(x_{n}, y_{n}\right)$ all of the data pairs are

209 taken in order from small to large for the explanatory variable $(x)$, from which are derived the

210 slopes $\left(B_{i j}\right)$ and the intercepts $\left(A_{i j}\right)$ for each pair, i.e.:

$211 \quad B_{i j}=\frac{\left(y_{j}-y_{i}\right)}{\left(x_{j}-x_{i}\right)} ; \quad$ where $i<j$

$212 \quad$ For each regression the $\left(\begin{array}{l}n \\ 2\end{array}\right)$ values of $B_{i j}$ are calculated as well as the same number of $A_{i j}$.

213 The median of the $B_{i j}$ values is taken as the slope of the straight-line regression and the median

214 of $\left(A_{i j}\right)$ as the intercept. In this study, the explanatory variable $(x)$ is either EMh or EMv; the

215 response variable $(y)$ is ECe.

216

217 Lateral distribution of soil salinity

219 Both ECe determined in the lab and estimated from EMI readings were kriged using Surfer

220 (Golden Software, Inc., Golden, CO) to obtain ECe contour lines. Study of the spatial statistics

221 is beyond our scope, but these lines allowed examination of the soil salinity distribution across

222 the plot. For the agricultural interpretation, we used the unequal soil salinity intervals

223 previously applied in a nearby area (Nogués et al. 2006) of the irrigation district, based on Soil

224 Survey Division Staff (1993).

225 


\section{Results and discussion}

228 Salinity and hydrology settings

230 The EMh values from the 14 ha farm were used to draw contour lines at intervals of $0.25 \mathrm{EMh}$

231 (Fig. 3). These contour lines of EMh can be indicators of soil salinity even before their

232 conversion to ECe according to our previous experience in the Flumen district (Díaz and

233 Herrero 1992; Lesch et al. 1992; Herrero et al. 2003; Playán et al. 2008) where linear

234 relationships between ECe and EMh were found. The map showed that plot no. 2, with 2.3-ha

235 extent, had the greatest variability of EMh among the plots, with an irregular growth of rye

236 grass and bare spots.

237 This map showed differences in the salinity pattern of the plots, related to the earth

238 movements needed to construct the leveled paddies no. 1 to no. 7. Plot no. 1 is $0.4 \mathrm{~m}$ higher in

239 elevation than plot no. 2. Ponding is more frequent in the areas with higher EMI readings.

240 Comparing an aerial image with this map, there was a good match with the vegetation cover

241 (Fig. 3).

242 When pipe T1 was installed in November 19, 1999, the water table was at $100 \mathrm{~cm}$ depth, 243 but it rose to within $50 \mathrm{~cm}$ of the surface after two hours (Fig. 5). The water level at T2 was at $24470 \mathrm{~cm}$ depth, and two hours later had risen to the soil surface. The water level remained 245 constant at $70 \mathrm{~cm}$ depth at pipe T3. The water table is confined under the densic pan, as shown 246 by the artesianism on November $20^{\text {th }}$. These observations illustrate the shallowness of the 247 water table and its quasi-artesian condition at the time of the field studies.

249 Exploratory data analysis

251 Examination of EMh vs. EMv gives some insight into differences in the vertical distribution of 252 soil features like salinity or moisture. EMh and EMv from the two dates, i.e., for the entire 253 farm and for plot no. 2, cannot be collated due to the 96 days elapsed between them involving 
254 changes in salts and water content in the soils. However, their distribution shapes and

255 measures of dispersion denote some differences between the whole farm and plot no. 2 (Fig.

256 6).

EMI readings and salinity measures

260 The frequency distributions of EMI readings for the farm $(50 \mathrm{~m} \times 50 \mathrm{~m}$ grid $)$ and for plot no. 2

261 (10 $\mathrm{m} \times 10 \mathrm{~m}$ grid) show similar skewness, but differ from the bimodal distributions of the

262 sampling sites. Bimodality also occurs within histograms of ECe.

263 For the 100 sites having EMI readings in the farm, both EMh and EMv have asymmetric

264 distributions tailing to the upper part, with EMv showing a broader range (Fig. 6). Values

265 greater than 2.25, considered high, are more frequent in EMv than in EMh, and the EMv

266 maximum is greater than the EMh maximum. The wider range and the other features of the

267 distribution of EMv compared with EMh can be related with the gradient of water and salt

268 content in the deep layers across the $800 \mathrm{~m}$ long farm. The different relationship for the 250

269 EMI reading sites at the plot scale may be due both to the smaller gradient and to the different 270 date of the readings.

271 For the 250 EMI reading sites from plot no. 2, EMh and EMv had similar ranges (Fig. 6)

272 with more than $60 \%$ of the values $<2.75$. The distributions were asymmetric and tailed to the

273 upper part. EMh and EMv had high variability, with coefficients of variation (CV) of $45 \%$ and

$27439 \%$, respectively. The many saline patches seen within the plot and the presence of an area

275 with no rye grass germination along the border with plot no. 1, support these CV's. The higher

276 CV for EMh can be attributed to a range of salinity or moisture in the plowed horizon greater

277 than in the densic pan or in the underneath saturated layers.

278 The distributions of EMh and EMv for the 40 augered sites were bimodal. These sites 279 were scattered all over the plot and through the range of salinity. This procedure did not 280 exactly preserve the distribution of the readings at the 250 sites in the plot, as shown by the 281 centrality measures of EMh and EMv higher at the 40 sampling sites than for the entire plot 282 no. 2 (Fig. 6), and by a greater interquartile range for the 40 sites. 
The range of EMh and EMv for the $10 \mathrm{~m} \times 10 \mathrm{~m}$ grid is higher than for the $50 \mathrm{~m} \times 50 \mathrm{~m}$ 284 grid of plot no. 2 (Fig. 6), mainly because of the higher values recorded from the $10 \mathrm{~m} \times 10 \mathrm{~m}$ 285 grid. Both features substantiate the variability of salinity, with saline areas not detected by the $28650 \mathrm{~m} \times 50 \mathrm{~m}$ grid.

Soil moisture

290 Gravimetric soil moisture $(\theta)$ determined at the lab on samples taken $(0-40 \mathrm{~cm})$ on December 29115,1999 ranged from $21 \%$ to $31 \%$, with an average of $26 \%$. These water contents are well 292 suited for calibrating the EM38 sensor to measure soil salinity (Rhoades et al. 1999). The 293 percent saturation (PS) of the saturated paste averaged 53\%, ranging from $34 \%$ to $63 \%$. This 294 large range shows the lateral variability of the texture of the upper soil layer within the studied 295 plot.

296 The regression of $\theta$ on PS obtained a low determination coefficient $\left(\mathrm{r}^{2}=0.18\right)$ and a non 297 significant slope $(\mathrm{p}=0.006)$. This result substantiates that the moisture of the studied soil layer 298 at the time of sampling was not controlled by texture. The soil moisture on the date when plot 299 no. 2 was sampled was heterogenous. It could be attributed to subtle leveling irregularities 300 within the plot, provided the lateral variability in the deep soil is smaller than in the shallow 301 layers, as suggested by comparing the coefficient of variation of EMh (45\%) versus EMv $302(39 \%)$ in the 250 reading sites.

303 The correlation between $\theta$ and EMh, EMv, and ECe at the 40 sampling sites was very 304 weak, with non-significant correlation coefficients of $0.217,0.174$, and 0.218 ( $\mathrm{p} \geq 0.176$ for 305 the three cases), showing that $\theta$ did not influence the EMI readings or the ECe measured in the 306 lab. The results were similar for the groupings of EMh and EMv profiles according to the two 307 proposed thresholds. 
311 Table 3 displays the analytical results for the analyzed samples ranked by their salinity. The

312 salinity range of these samples was high, as shown either by their ECe ranging from 2.96 to

$31320.80 \mathrm{dS} \mathrm{m}^{-1}$, or by the content of the plant-stressing ions $\mathrm{Mg}^{2+}, \mathrm{Na}^{+}, \mathrm{Cl}^{-}$, and $\mathrm{SO}_{4}{ }^{2-}$. The $\mathrm{pHe}$

314 ranged from 7.97 to 8.18. Clays remain flocculated at these $\mathrm{pH}$ values and such high salt

315 content levels. The ranking of sites by salinity is the same as by SAR. Using soil salinity

316 classes listed by the Soil Survey Division Staff (1993, page 193), the mean ECe of these

317 samples $\left(10.8 \mathrm{dS} \mathrm{m}^{-1}\right)$ qualifies as strongly saline, with all individual ECe greater than the $2 \mathrm{dS}$

$318 \mathrm{~m}^{-1}$ threshold for slightly saline soils. Two samples surpassed the $16 \mathrm{dS} \mathrm{m}^{-1}$ threshold for very

319 strongly saline soils. Only two samples have $\mathrm{SAR}<13$; all the others are classified as sodic

320 (United States Salinity Laboratory Staff 1954). These two samples have by far the lowest ECe

321 and PS, illustrating the relationship of salinity and soil texture surrogated by PS.

323 Relationships between EMh and EMv

325 We maintain the widespread terms "regular/inverted profile" (Rhoades et al. 1999) for the 326 deep/shallow soil predominance of the EMI signal, even though the contribution of the 327 horizons is related to both water and salt content. The scatter plots of EMv and EMh are 328 presented in Fig. 7a and b for the 100 reading sites across the entire farm, in Fig. 7c and $d$ for 329 the 250 reading sites in the plot no. 2. Crosses or circles in these figures stand for sites with a 330 regular or an inverted profile using two different thesholds: (i) sites where EMv $\geq \mathrm{EMh}$, and 331 (ii) sites where $\mathrm{EMv} \geq \mathrm{EMh}+0.1$. For the entire farm (Fig. 7a and b), regular profiles look 332 better adjusted to a straight line than all the 100 sites together. In contrast, the small number of 333 observations (circles in Fig. 7a) or the bimodal distribution (circles in Fig. 7b) of EMh and 334 EMv of the inverted profiles prevent the study of these relationships.

335 The direct comparison of readings at plot no. 2 with the 100 above-discussed readings is 336 impossible because of the different dates and areas of measurement. However, groups of 337 regular and inverted profiles show some similarities if Fig. 7c and d is compared with Fig. 7a 338 and $b$. The regular profile data fit better when adjusted to a straight line than the inverted 
profiles do, even for the 250 sites (Fig. 7c and d), which have a non-bimodal distribution and many more observations than Fig. $7 \mathrm{a}$ and $\mathrm{b}$.

341 The considerations of the two above paragraphs apply better for the arbitrary threshold

$342 \mathrm{EMv} \geq \mathrm{EMh}+0.1$. The regressions of EMv on EMh were calculated separately for the 100

343 reading sites on the farm, the 250 reading sites from the plot, and the 40 sites with soil samples

344 (Table 4). Moreover, regressions were also calculated after splitting the sites according to the

345 two above criteria. A high coefficient of determination means a high colinearity of the two

346 readings. The second criterion $(\mathrm{EMv} \geq \mathrm{EMh}+0.1)$ classified fewer sites as having high

347 contribution to the EMI readings from the deep layers. For the farm, i.e., 100 EMI reading

348 sites, only the second criterion allowed comparison of colinearity, but the difference was small

$349\left(r^{2}=0.97\right.$ versus $\left.r^{2}=0.99\right)$. For plot no. 2, i.e., 250 EMI reading sites, and their augered sites,

350 i.e., 40 EMI reading sites, these groupings show more colinearity for sites with a high

351 contribution from the deep layers, both for the plot and for the augered sites, and the stricter

352 the criterion the higher the colinearity.

353 The coherence of all parameters in Table 4 gives some credit even to those equations

354 with a low number of observations, and also supports the thesis that the 40 augering sites are

355 representative of plot no. 2. The colinearity for sites having EMv $\geq \mathrm{EMh}$, or $\mathrm{EMv} \geq \mathrm{EMh}+0.1$

356 can be related to water ponding at several of these sites, and with gravimetric water content $>$

$35728 \%$ for the upper horizon. The reason is that ponding could mask the high contribution to

358 EMI readings from deep layers supersaturated with saline water.

359 The equations obtained for the 250 reading sites and the 40 augered sites (Table 4), are 360 quite similar. The equations for sites with $\mathrm{EMv} \geq \mathrm{EMh}$ or with $\mathrm{EMv} \geq \mathrm{EMh}+0.1$ are almost 361 the same if either all the sites or only the augered ones are computed. The differences are 362 greater in the equations of shallow soil predominant probably because of the low number of 363 observations. These relationships support the representativity of the 40 sites.

365 Calibrations of EM38 
367 The regressions of EMh and EMv on ECe (Table 5) convey the coherence of field

368 measurements and lab determinations. The two last columns of this Table show the differences

369 between least squares and Theil adjustments for both the intercept and the slope. The greater

370 differences occur in Eq. 3, with only four samples and a non-significant slope $(p=0.143)$.

371 In spite of the colinearity between EMh and EMv discussed in the preceding section,

372 Table 5 shows that the adjustments for EMh attain a higher $r^{2}$ and lower standard error (SE)

373 than for EMv, i.e.: Eqs. 1, 2, 3, 4, and 5 vs. Eq. 6. The SE's of the EMh adjustments are

374 smaller than for the EMv adjustment, except in Eq. 3, with only 4 effectives and with both

375 intercept and slope non-significant.

376 The $\mathrm{r}^{2}=0.86$ obtained by regressing ECe on EMh for all augered sites (Eq. 1) rises if

377 only regular profiles according to either of the two considered thresholds are computed (Eqs. 2

378 and 4); SE's are also improved. The improvement in $r^{2}$ and SE obtained with the separate

379 calibration for regular profiles after the first threshold (Eq. 2) seems promising. However, this

380 result is not conclusive because the first threshold gives only 4 inverted profiles (Eq. 3, with

381 no significant parameters), and the second threshold (Eq. 5) yields a worse adjustment for

382 inverted profiles than Eq. 1. As expected, the adjustment with EMv (Eq. 6) is less satisfying

383 than with EMh (Eq. 1). Strong (20\%) decrease in $r^{2}$ in the predictions of ECe occurs when

384 using EMv instead of EMh (Eq. 1 vs. Eq. 6). This can be attributed to the effect on the EMI

385 signal produced by the supersaturated and saline horizon below $40 \mathrm{~cm}$, with much more

386 relative contribution to EMv than to EMh.

387 The multiple linear regressions of the direct salinity measures, ECe, on EMh and EMv,

388 give coefficients significant at $\mathrm{p}<0.001$ only for EMh, as expected from the simple linear

389 regression equations discussed in the above paragraph. The improvements of $\mathrm{r}^{2}$ and SE against

390 simple linear regression are slight. For ECe, the improvements of $0.8 \%$ in $\mathrm{r}^{2}$ and $0.03 \mathrm{dS} \mathrm{m}^{-1}$ in

391 the SE are well under the improvements of $4 \%$ for $\mathrm{r}^{2}$ and $0.36 \mathrm{dS} \mathrm{m}^{-1}$ for SE obtained for

392 regular profiles using the first threshold (Table 5, Eq. 2). The multiple linear regressions with

393 the log transformed variables EMh and EMv did not obtain better results.

394 The calibration by the least squares regression obtain equations similar to Theil method,

395 but this distribution-free method is preferred because Box-Cox transformations, logarithmic 
transformations, or multiple linear regressions either did not meet the statistical requirements for variables' distribution, or obtained not better adjustments than Theil method.

The last two columns of Table 5 show the differences between the intercepts $\left(a-a_{T}\right)$ and between the slopes $\left(b-b_{T}\right)$ calculated by the least squares and by the Theil estimator. This difference is disregarded for Eq. 3, because both $a$ and $b$ coefficients are not significant. The greater discrepancies in the slopes occur in Eqs. 4 and 5, with about 7\% of $b$ while all the others are $<1.5 \%$ of $b$. The low signification of intercepts in the simple linear regressions, plus the small differences between $b$ and $b_{T}$, allow one to discard the intercepts and to use slopes calculated by Theil method. The results of the threshold EMv $<$ EMh +0.1 that produces for the studied plot an increased number of inverted profiles (Table 5, Eqs. 4 and 5) advocate that this technique merits further efforts.

The centrality and dispersion measures for the ECe estimations for the 250 sites within the plot no. 2 can be compared with the same measures of the 40 ECe lab-determinations. The means of the 40 lab determinations of ECe is $7.88 \mathrm{dS} \mathrm{m}^{-1}$ against $8.11 \mathrm{dS} \mathrm{m}^{-1}$ of the estimations by Theil regression for the 250 reading sites, and the values of the medians are $6.38 \mathrm{dS} \mathrm{m}^{-1}$ against $7.21 \mathrm{dS} \mathrm{m}^{-1}$, respectively. These differences are allowable for agricultural purposes. The dispersion measures of the 40 lab determinations and the same measures of the estimations for the 250 sites show a much great dispersion for the 40 lab measures. This happens because the 40 sampling sites were not randomly selected, but were selected to cover the full range of soil salinity appraised from our first EMI survey and field visits.

The low number of observations, a common circumstance for the small-sized fields of Mediterranean agriculture, hampered the separate calibration for "regular" and "inverted" profiles. The separate calibration, however, seems promising as shown by the results obtained with the two assayed thresholds. This black-box approach encompasses the effects of the saline water table and other soil features on the EMI signal, and can be easily tested when further, similar paddies are studied. Other thresholds, either arbitrary or arising from new designs of electromagnetic induction sensors, could be assayed for regrouping profiles for separate adjustments with ECe. 
The map resulting from the 40 ECe lab-determined values has to be compared with the 425 map resulting from these values plus the estimations at the remaining 210 EMI sites using the 426 Theil method (Fig. 8). Both maps in this Figure show the soil salinity classes relevant for 427 agriculture (Soil Survey Division Staff 1993), with an overall agreement between the map 428 without EMI data and that produced incorporating EMI data, and with the classical better 429 detail furnished by the much greater number of sites with estimates obtained from EMI 430 readings. A noticeable difference from this degree of detail is the more elongated shape and 431 parallel disposition of the saline patches. This salinity pattern is attributed to the effect of past 432 land cutting and levelling combined with the several non-fully functional parallel subsurface 433 drainage pipes outlets to the drainage ditch. We deem the map of Fig. $8 \mathrm{~b}$ as the most reliable.

\section{Conclusions}

437 The soil salinity of the targeted rootable horizon of a paddy with a densic pan underlayed by a 438 supersaturated and saline layer can be mapped with a non-deterministic approach using 439 electromagnetic induction. This approach did not need assumptions about the salinity 440 distribution through the soil profile, or about the nature of the EM38 signal, or about the 441 normality of the regressed variables. The readings of the EM38 sensor were calibrated with the 442 soil salinity expressed as ECe of the targeted $40 \mathrm{~cm}$ depth. The similarity of the adjustments 443 by the non-parametric Theil adjustment and by LSR agrees with previous results for nearby 444 areas.

445 The rootable horizon of the studied paddy is strongly or very strongly saline (ECe $\geq 8 \mathrm{dS}$ $446 \mathrm{~m}^{-1}$ ) in about a half the surface area. Only halophytes grow well in these conditions, and rice 447 with running fresh water remains the only profitable crop. There is still lateral variability of 448 soil salinity in spite of the long history of puddling and yearly inundation with running fresh 449 irrigation water. However, the salinity of the upper soil layer of the studied plot is more 450 homogeneous than in the nearby more recent paddies. The variability of soil salinity, not 451 mirrored by the rice plants development, has been depicted with EMI measurements and a few 452 soil samples. 
The successful mapping for the upper $40 \mathrm{~cm}$ layer, in spite of the oversaturation by saline water under the densic pan, proves that EMI is a powerful tool for further salinity mapping in paddies. It will enable future studies to highlight the evolution of soil salinity with

456 a reduced number of soil samples. The main limitation for field surveying is paddy trafficability, a condition that occurs only occasionally, and not in all paddies at the same time.

These kinds of maps will allow for future monitoring of soil salinity both for environmental purposes and as a key soil feature to avoid fiascos when planting crops other 460 than rice.

Acknowledgements. Field and lab works were done at the Soils and Irrigation Unit, Zaragoza, 463 Spain. This article was funded by the Spanish Government (project AGL2012-40100) and by grant 464 FMI33/11 from Aragon, Spain. Thanks to Ms. Rosa Gómez for her help with the figures.

\section{REFERENCES}

467 Aimrun W, Amin MSM, Ezrin MH, Mastura M (2011) Paddy soil properties and yield

468 characteristics based on apparent electrical conductivity zone delineation for a humid 469 tropical rice farm. African J Agric Res 6: 5339-5350.

470 Aimrun W, Amin MSM, Ahmad D, Hanafi MM, Chan CS (2007) Spatial variability of bulk 471 soil electrical conductivity in a Malaysian paddy field: key to soil management. Paddy $472 \quad$ Water Environ 5: 113-121.

473 Amezketa E (2006) An integrated methodology for assessing soil salinization, a pre-condition for 474 land desertification. J Arid Environ 67:594-606.

475 Chambers JM, Cleveland WS, Kleiner B, Tukey PA (1983) Graphical methods for data 476 analysis. Chapman and Hall, New York.

477 Daniel WW (1990) Applied nonparametric statistics, $2^{\text {nd }}$ ed. Pws-Kent Publ Co. Boston, MA.

478 Díaz L, Herrero J (1992) Salinity estimates in irrigated soils using electromagnetic induction. $479 \quad$ Soil Sci 154:151-157. 
480 Enrique A, Bescansa P, Virto I (2005) Measuring salinity using electromagnetic sensors for 481 sustainable management of rice fields in the Ebro River Basin, NE Spain. Adv Geoecol $482 \quad 36: 559-567$.

483 Ezrin MSM, Amin MSM, Anuar AR, Aimrun W (2010) Relationship between Rice Yield and 484 Apparent Electrical Conductivity of Paddy Soils. Am J Appl Sci 7: 63-70.

485 Glaister P (2005) A comparison of best fit lines for data with outliers. Internat. J. Math.

486 Education Sci Techn 36:110-117.

487 Herrero J (2008) Salinidad edáfica en varios salobrares de Aragón. Memorias de la Real

488 Sociedad Española de Historia Natural 4:1-164. Madrid, Spain. (In Spanish).

489 Herrero J, Pérez-Coveta O (2005) Soil salinity changes over 24 years in a Mediterranean $490 \quad$ irrigated district. Geoderma 125:287-308.

491 Herrero J, Ba AA, Aragüés R (2003) Soil salinity and its distribution determined by soil 492 sampling and electromagnetic techniques. Soil Use Manage 19:119-126.

493 Herrero J, Netthisinghe A, Hudnall WH, Pérez-Coveta O (2011) Electromagnetic induction as 494 a basis for soil salinity monitoring within a Mediterranean irrigation district. J Hydrol $495 \quad 405: 427-438$.

496 Isaaks EH, Srivastava RM (1989) An introduction into applied geostatistics. Oxford 497 University Press, New York.

498 Islam MM, Cockx L, Meerschman E, De Smedt P, Meeuws F, Van Meirvenne M (2011) A

499 floating sensing system to evaluate soil and crop variability within flooded paddy rice $500 \quad$ fields. Precis Agr 12: 850-859.

501 Lesch SM, Corwin DL, Robinson DA (2005) Apparent soil electrical conductivity mapping as 502 an agricultural management tool in arid zone soils. Comput Electron Agr 46:351-378.

503 Lesch SM, Rhoades JD, Lund LJ (1992) Mapping soil-salinity using electromagnetic 504 measurements. Soil Sci Soc Am J 56:540-548.

505 Li HY, Shi Z, Webster R, Triantafilis, J (2013) Mapping the three-dimensional variation of soil 506 salinity in a rice-paddy soil. Geoderma 195-196:31-41. 
López-Bruna D, Herrero J (1996) El comportamiento del sensor electromagnético y su calibra-

508 ción frente a la salinidad edáfica. Agronomie 16:95-105. (In Spanish, with English summary).

509 McNeill JD (1980) Electromagnetic terrain conductivity measurement at low induction

510 numbers. Technical Note 6. Geonics Ltd. Ontario, Canada (http://www.geonics.com)

511 Myers RH (1990) Classical and modern regression with applications. $2^{\text {nd }}$ ed. Wadsworth

512 Publishing Company. Belmont, CA.

513 Nogués J, Robinson DA, Herrero J (2006) Incorporating electromagnetic induction methods

514 into regional soil salinity survey of irrigation districts. Soil Sci Soc Am J 70:2075-2085.

515 Nogués J, Herrero J, Rodríguez-Ochoa R, Boixadera J (2000) Land evaluation in a salt-

516 affected irrigated district using an index of productive potential. Environ Manage 25:143$517 \quad 152$.

518 Playán E, Pérez-Coveta O, Martínez-Cob A, Herrero J, García-Navarro P, Latorre B, Brufau

519 P, Garcés J (2008) Overland water and salt flows in a set of rice paddies. Agr Water

520 Manage 95:645-658.

521 Rhoades JD, Chanduvi F, Lesch SM (1999) Soil salinity assessment. Methods and interpretation 522 of electrical conductivity measurements. FAO Irrigat Drainage Paper 57. FAO, Rome, Italy.

523 Soil Survey Staff (2010) Keys to Soil Taxonomy, $11^{\text {th }}$ ed. Natural Resources Conservation 524 Service, USDA. Washington, DC.

525 Soil Survey Division Staff (1993) Soil survey manual. Natural Resources Conservation 526 Service, Handbook 18. USDA. Washington, DC.

527 United States Salinity Laboratory Staff (1954) Diagnosis and improvement of saline and alkali 528 soils. Agriculture Handbook no. 60. USDA. Reprint 1969. 


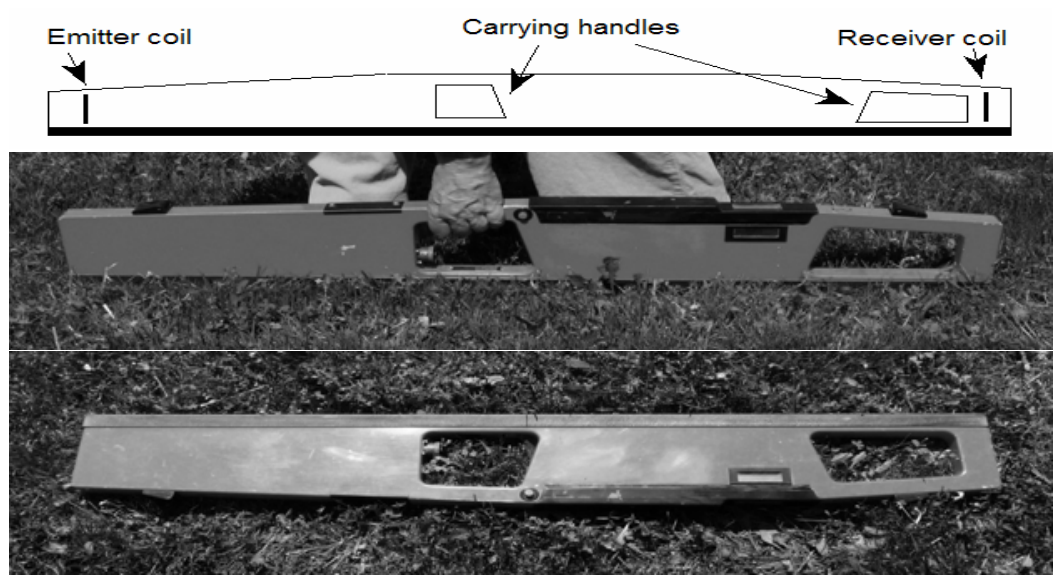

Fig. 1 Diagram of an EM38 sensor (a), the EM38 in vertical (b) and horizontal (c) position.

Fig. 2 Location of the Flumen irrigation district in the Ebro Valley, Spain
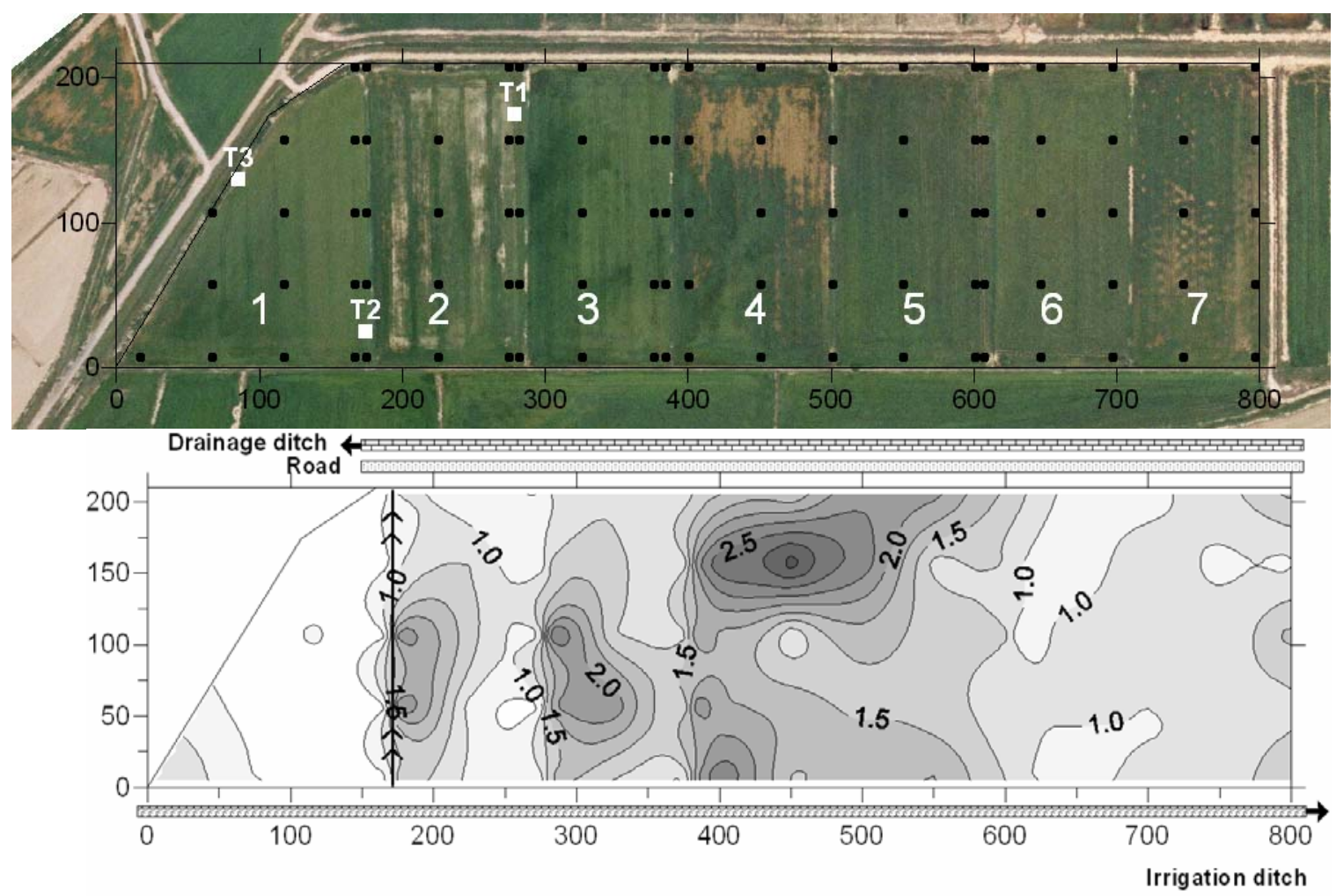

Fig. 3 The aerial image of the farm in 2006 shows the plot numbers and the observation wells (T1, T2, and T3) in white; black circles mark the EMI reading sites. The EMh map (axes in meters) of the entire farm was obtained from EM38 readings in September 10, 1999. Arrows on the ditches and the pipe drain show the water flow direction. 


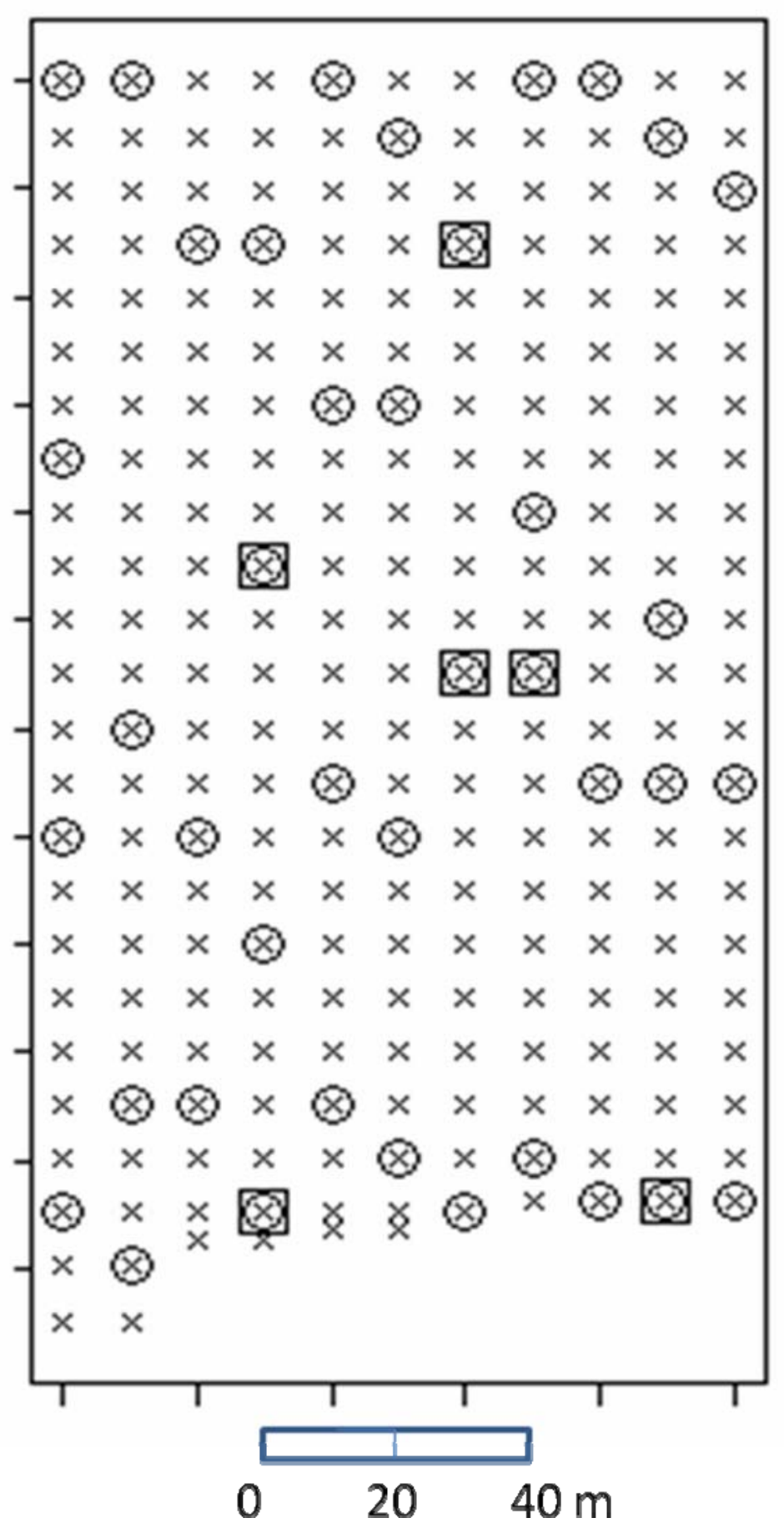

Fig. 4 Distribution of the 250 EMI readings (crosses) within the plot no. 2. Soil samples were also taken at 40 of these sites, marked with circles, for $\theta$, PS, and ECe determination. Other chemical analyses (Table 2) were performed on the samples from the sites marked with squares. 


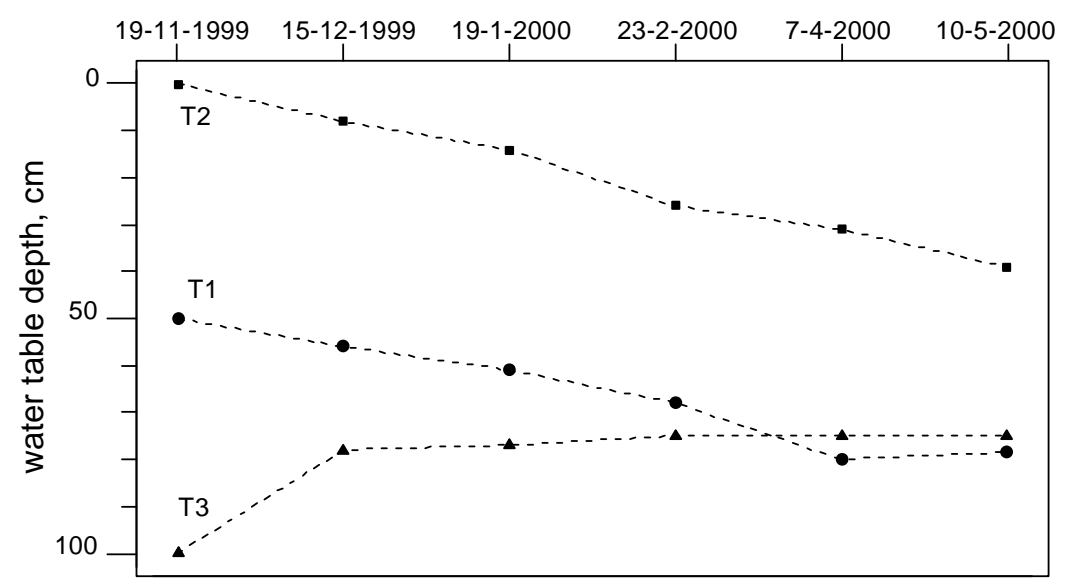

559

560

561

562

563

564

565

566
Fig. 5 Water table depth at six dates in the three observation pipes T1, T2, and T3.

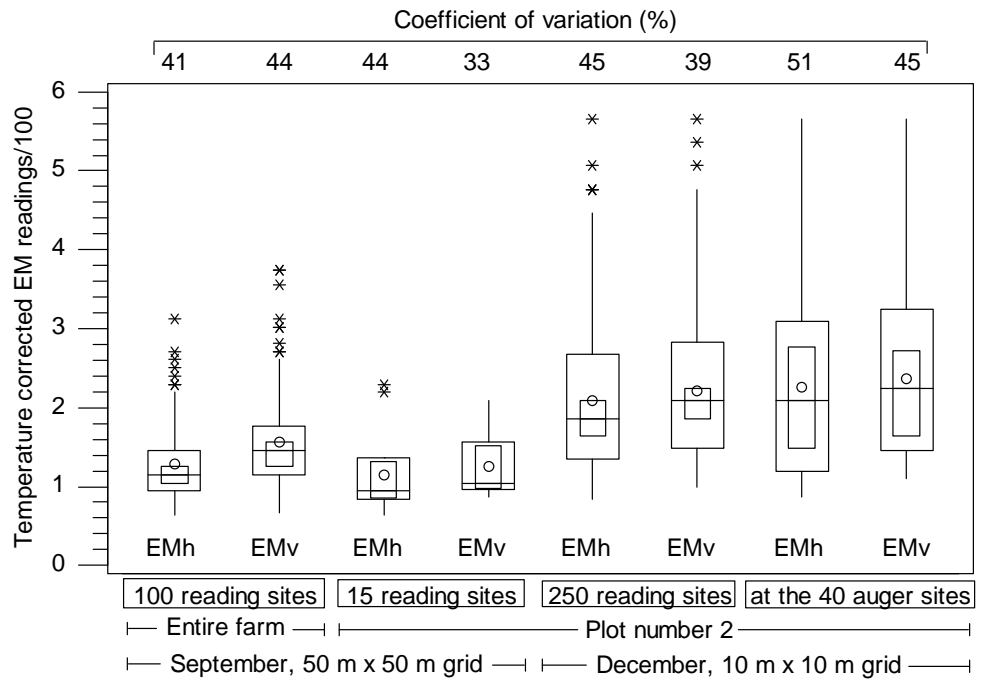

Fig. 6 Boxplots of EMh and EMv (i) at the 100 reading sites in the entire farm with $50 \mathrm{~m}$ $\times 50$ m orthogonal grid, (ii) at 15 of these sites falling within plot no. 2, (iii) at the 250 reading sites within plot no. 2, and (iv) at the 40 of those sites where soil cores were taken immediately after the EMI readings. 
568

569
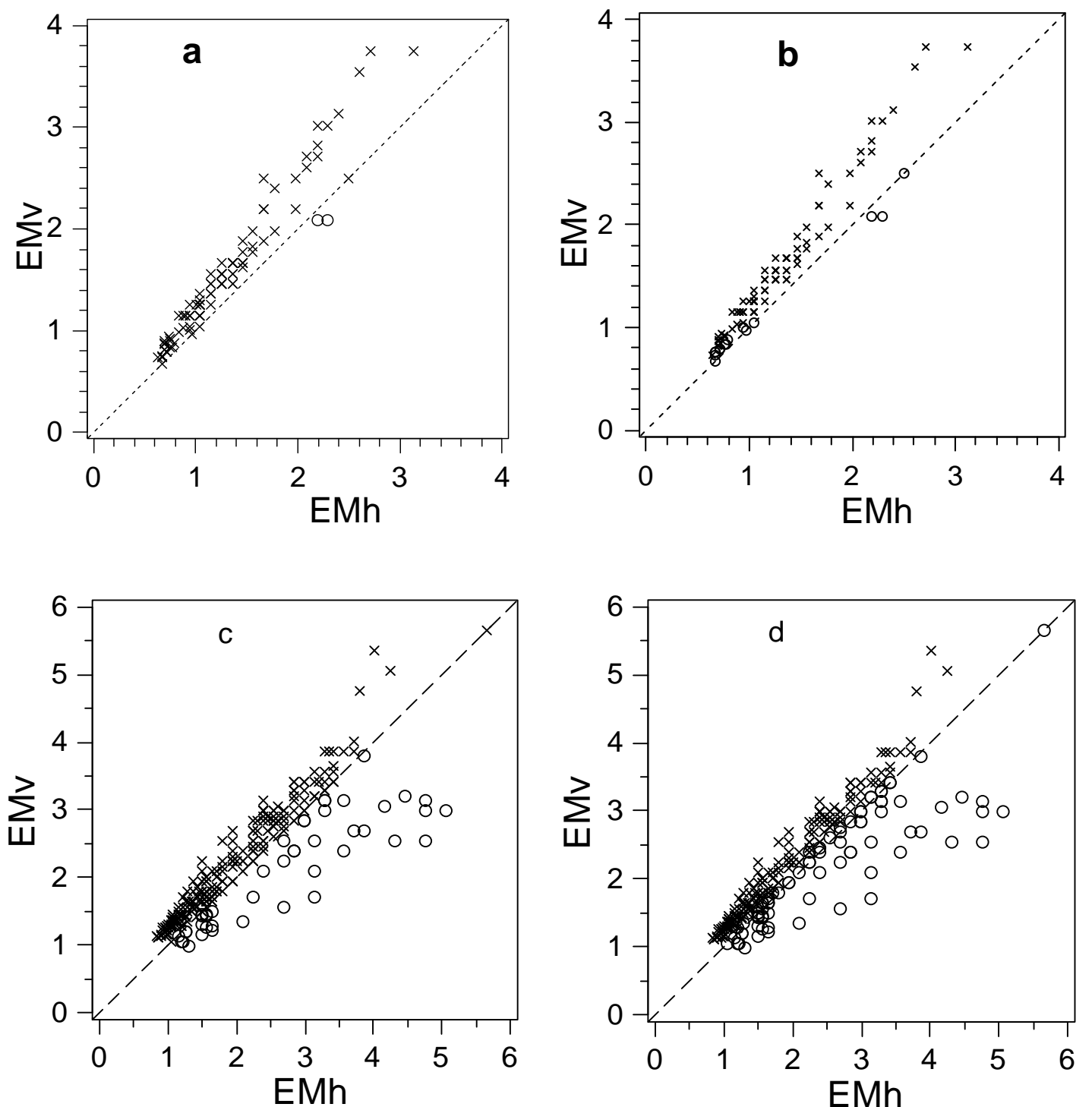

Fig. $7 \mathrm{EMh}$ and EMv at the 100 reading sites in the farm (a and b), and at the 250 reading sites in the studied plot ( $\mathrm{c}$ and $\mathrm{d}$ ). Crosses at the graphs a and $\mathrm{c}$ are for those sites where EMv $\geq E M h$; crosses at the graphs $b$ and $d$ are for sites where EMv $\geq E M h+0.1$. Circles are for sites with EMv below the mentioned thresholds. Dashed line is EMv $=\mathrm{EMh}$. 
a

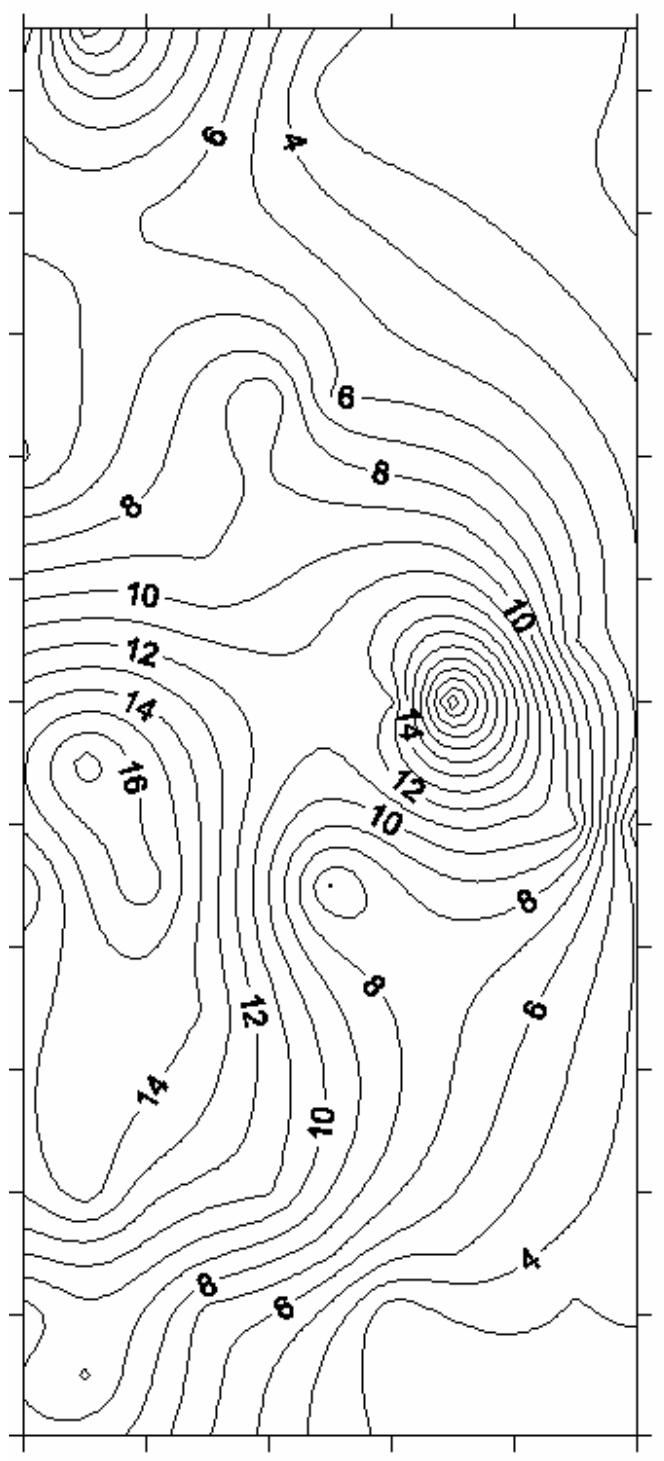

b

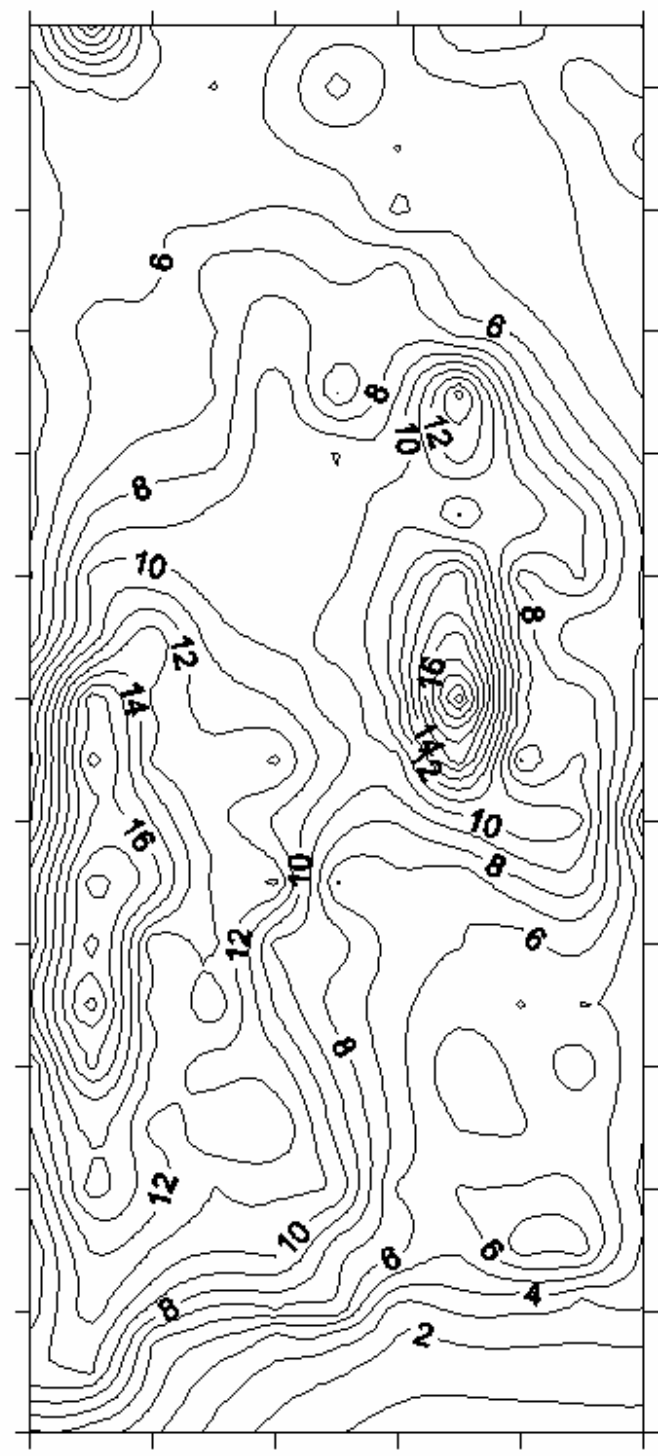

578

579

580

581 582

Fig. 8 Contour lines of ECe $\left(\mathrm{dS} \mathrm{m} \mathrm{m}^{-1}\right)$ obtained from the lab determinations at the 40 augered sites (Map a), and from the same data plus the estimates at the remaining 210 sites with Theil slope estimator (Map b). Bar scale is in meters. 
607 Table 1 Analytical results for the soil profile at plot no. 1.

\begin{tabular}{|c|c|c|c|c|c|c|c|c|c|c|}
\hline \multicolumn{11}{|c|}{ Samples taken in 1979 , before conversion in a paddy } \\
\hline \multirow{2}{*}{ Horizon } & Depth & $\mathrm{OM}$ & $\mathrm{pH}$ & CCE & PS & $\mathrm{ECe}$ & $\mathrm{Ca}^{2+}$ & $\mathrm{Mg}^{2+}$ & $\mathrm{Na}^{+}$ & \multirow{2}{*}{$\begin{array}{c}\text { SAR } \\
\left(\text { meq } \mathrm{L}^{-1}\right)^{0.5}\end{array}$} \\
\hline & $\mathrm{cm}$ & $\%$ & $1: 2.5$ & $\%$ & $\%$ & $\mathrm{dS} \mathrm{m}{ }^{-1}$ & \multicolumn{3}{|c|}{ meq $L^{-1}$} & \\
\hline Ap & $0-7$ & 1.20 & 9.10 & 22 & 60.0 & 99.83 & 36.0 & 74.0 & 1391.3 & 188 \\
\hline BA & $7-43$ & 0.66 & 8.94 & 23 & 58.0 & 36.25 & 30.5 & 24.0 & 380.4 & 73 \\
\hline $\mathrm{B} 2$ & $43-84$ & 0.38 & 9.05 & 26 & 60.5 & 32.71 & 29.0 & 23.5 & 391.3 & 76 \\
\hline $\mathrm{C}$ & $84-110$ & 0.13 & 9.13 & 27 & 42.0 & 35.58 & 28.8 & 22.8 & 434.8 & 86 \\
\hline Cy & $110-120$ & 0.26 & 9.02 & 27 & 58.0 & 37.13 & 29.5 & 25.0 & 460.9 & 88 \\
\hline Cy & $138-145$ & 0.25 & 8.99 & 23 & 62.0 & 37.45 & 32.2 & 16.7 & 469.6 & 95 \\
\hline
\end{tabular}

$608 \overline{\mathrm{OM}}=$ organic matter; $\mathrm{CCE}=$ calcium carbonate equivalent; $\mathrm{PS}=$ percent saturation; $\mathrm{ECe}=$ 609 electrical conductivity of the saturation extract; SAR = sodium adsorption ratio.

610

611

612

\begin{tabular}{ccccccc}
\hline \multicolumn{7}{c}{ Average ECe $\left(\mathrm{dS} \mathrm{m}^{-1}\right)$ for consecutive soil layers } \\
\hline Depth, $\mathrm{cm}$ & $0-20$ & $20-40$ & $40-60$ & $60-80$ & $80-100$ & $100-120$ \\
\hline $1979-1980$ & 50.54 & 37.01 & 31.01 & 29.34 & 33.17 & 26.40 \\
\hline $1999-2000$ & 3.15 & 1.67 & 1.08 & 1.18 & 1.42 & 1.87 \\
\hline
\end{tabular}

613

614 Table 2 Observations performed on the studied farm in 1999.

615

\begin{tabular}{ccccccc}
\hline Date & $\begin{array}{c}\text { Surface } \\
\text { extent, ha }\end{array}$ & $\begin{array}{c}\text { Grid, } \\
\mathrm{m} \times \mathrm{m}\end{array}$ & $\begin{array}{c}\text { EM38 readings } \\
\text { horizontal } \\
\text { dipole }\end{array}$ & $\begin{array}{c}\text { vertical } \\
\text { dipole }\end{array}$ & Number & $\begin{array}{c}\text { Depth, } \\
\text { cm }\end{array}$ \\
\hline 10 September & 14 & $50 \times 50$ & 100 & 100 & 0 & - \\
15 December & 2 & $10 \times 10$ & 250 & 250 & 40 & $0-40$ \\
\hline
\end{tabular}

616

617 Table 3 Analytical results for six of the 40 soil samples taken on December 15, 1999 from the 618 surface layer $(0-40 \mathrm{~cm})$ of the studied plot no 2.

\begin{tabular}{ccccccccccc}
\hline $\begin{array}{c}E C e \\
\mathrm{dS} \mathrm{m}\end{array}$ & PS & $\mathrm{pHe}$ & $\mathrm{Ca}^{2+}$ & $\mathrm{Mg}^{2+}$ & $\mathrm{Na}^{+}$ & $\mathrm{HCO}_{3}^{-}$ & $\mathrm{Cl}^{-}$ & $\mathrm{SO}_{4}^{2-}$ & \begin{tabular}{c}
$\mathrm{SAR}$ \\
\cline { 5 - 10 }$\left(\mathrm{meq} \mathrm{L}^{-1}\right)^{0.5}$
\end{tabular} \\
\hline 2.96 & 42 & 8.18 & 15.7 & 6.8 & 10.8 & 2.6 & 7.4 & 24.5 & 3.23 \\
3.63 & 51 & 8.13 & 11.3 & 10.4 & 20.6 & 2.4 & 9.9 & 31.8 & 6.26 \\
9.13 & 62 & 7.95 & 19.0 & 22.1 & 70.6 & 1.8 & 42.2 & 79.6 & 15.59 \\
11.75 & 61 & 8.02 & 12.7 & 30.4 & 105.0 & 2.2 & 57.7 & 96.3 & 22.62 \\
16.60 & 58 & 7.92 & 23.7 & 40.9 & 158.5 & 2.0 & 92.9 & 140.2 & 27.90 \\
20.80 & 56 & 7.97 & 16.7 & 44.0 & 223.7 & 1.4 & 110.8 & 182.9 & 40.58 \\
\hline
\end{tabular}


621 Table 4 Regression equations (EMv $=a+b \times \mathrm{EMh}$ ), number of computed sites (n) and percent of the 622 total number of observations (\% $\mathrm{n})$, coefficient of determination $\left(\mathrm{r}^{2}\right)$, and standard error (SE) in $\mathrm{dS} \mathrm{m}^{-}$ $623{ }^{1}$. Two different criteria $(\mathrm{EMv} \geq \mathrm{EMh}$, and $\mathrm{EMv} \geq \mathrm{EMh}+0.1)$ were assayed for assigning sites to the 624 class "high contribution of deep soil to EMI readings".

\begin{tabular}{|c|c|c|c|c|c|c|}
\hline Computed & $\mathrm{n}$ & $\% \mathrm{n}$ & $a$ & $b$ & $\mathrm{r}^{2}$ & SE \\
\hline & \multicolumn{6}{|c|}{ The entire farm; September 10, 1999} \\
\hline All readings & 100 & & $-0.058(0.190)$ & 1.250 & 0.94 & 0.17 \\
\hline $\mathrm{EMv} \geq \mathrm{EMh}$ & 98 & 98 & $-0.107(0.005)$ & 1.299 & 0.96 & 0.14 \\
\hline $\mathrm{EMv}<\mathrm{EMh}$ & 2 & 2 & & & & \\
\hline $\mathrm{EMv} \geq \mathrm{EMh}+0.1$ & 85 & 85 & $-0.113(0.004)$ & 1.316 & 0.97 & 0.12 \\
\hline \multirow[t]{2}{*}{$\mathrm{EMv}<\mathrm{EMh}+0.1$} & 15 & 15 & 0.131 & 0.902 & 0.99 & 0.05 \\
\hline & \multicolumn{6}{|c|}{ The studied plot; December 15, 1999} \\
\hline All readings & 250 & & 0.544 & 0.798 & 0.76 & 0.42 \\
\hline $\mathrm{EMv} \geq \mathrm{EMh}$ & 206 & 82 & 0.213 & 1.033 & 0.95 & 0.19 \\
\hline $\mathrm{EMv}<\mathrm{EMh}$ & 44 & 18 & $0.496(0.002)$ & 0.593 & 0.77 & 0.38 \\
\hline $\mathrm{EMv} \geq \mathrm{EMh}+0.1$ & 170 & 68 & 0.180 & 1.079 & 0.97 & 0.16 \\
\hline \multirow[t]{2}{*}{$\mathrm{EMv}<\mathrm{EMh}+0.1$} & 80 & 32 & 0.503 & 0.673 & 0.74 & 0.43 \\
\hline & \multicolumn{6}{|c|}{ Only the augered sites; December 15,1999} \\
\hline All readings & 40 & & $0.465(0.004)$ & 0.839 & 0.84 & 0.44 \\
\hline $\mathrm{EMv} \geq \mathrm{EMh}$ & 36 & 90 & $0.242(0.001)$ & 0.988 & 0.98 & 0.17 \\
\hline $\mathrm{EMv}<\mathrm{EMh}$ & 4 & 10 & $0.776(0.123)$ & $0.416(0.046)$ & 0.91 & 0.27 \\
\hline $\mathrm{EMv} \geq \mathrm{EMh}+0.1$ & 26 & 65 & $0.195(0.002)$ & 1.050 & 0.99 & 0.13 \\
\hline $\mathrm{EMv}<\mathrm{EMh}+0.1$ & 14 & 35 & $0.441(0.274)$ & 0.753 & 0.75 & 0.59 \\
\hline
\end{tabular}

Table 5 Ordinary least squares regression equations $(\mathrm{ECe}=a+b \times \mathrm{EM})$ of $\mathrm{ECe}$ on $\mathrm{EMh}$ and $630 \mathrm{EMv}$, with the number of computed sites (n), coefficient of determination $\left(\mathrm{r}^{2}\right)$, and standard 631 error (SE), followed by the differences with the Theil's estimation of intercept $\left(a-a_{T}\right)$ and slope 632

633 $\left(b-b_{T}\right)$.

\begin{tabular}{|c|c|c|c|c|c|c|c|c|}
\hline $\begin{array}{l}\text { Eq. } \\
\#\end{array}$ & $\begin{array}{l}\text { Independent } \\
\text { variable }\end{array}$ & $\mathrm{n}$ & $a$ & $b$ & $r^{2}$ & $\begin{array}{c}\mathrm{SE} \\
\mathrm{dS} \mathrm{m} \mathrm{m}^{-1}\end{array}$ & $a-a_{T}$ & $b-b_{T}$ \\
\hline 1 & EMh & 40 & $-0.726(0.266)$ & 3.816 & 0.86 & 1.84 & $\overline{0.451}$ & -0.055 \\
\hline 2 & $\begin{array}{c}\mathrm{EMh} \\
\text { (only EMv } \geq \mathrm{EMh} \text { ) }\end{array}$ & 36 & $-1.154(0.046)$ & 3.903 & 0.90 & 1.48 & 0.110 & 0.042 \\
\hline 3 & $\begin{array}{c}\text { EMh } \\
\text { (only EMv < EMh) }\end{array}$ & 4 & $4.580(0.345)$ & $2.716(0.143)$ & 0.74 & 3.41 & 3.384 & -0.703 \\
\hline 4 & $\begin{array}{c}\mathrm{EMh} \\
(\text { only } \mathrm{EMv} \geq \mathrm{EMh}+0.1)\end{array}$ & 26 & $-1.070(0.127)$ & 3.774 & 0.86 & 1.51 & 0.003 & 0.226 \\
\hline 5 & $\begin{array}{c}\text { EMh } \\
(\text { only } \mathrm{EMv}<\mathrm{EMh}+0.1)\end{array}$ & 14 & $1.091(0.457)$ & 3.448 & 0.82 & 2.19 & 1.244 & -0.259 \\
\hline 6 & EMv & 40 & $-0.682(0.541)$ & 3.631 & 0.65 . & 2.85 & 1.007 & 0.017 \\
\hline
\end{tabular}

634 Significance levels of $a$ and $b$ are indicated in parenthesis whenever $>0.0001$. 